\title{
Produção de cebola cultivada sob diferentes densidades de plantio
}

\author{
Gabrielly P. de S. A. Henriques ${ }^{1}$, Leilson C. Grangeiro ${ }^{2}$, Renan da C. Paulino 3 , \\ Saulo de T. P. Marrocos ${ }^{4}$, Valdívia F. L. de Sousa ${ }^{5} \&$ Rayanne M. P. Ribeiro ${ }^{6}$
}

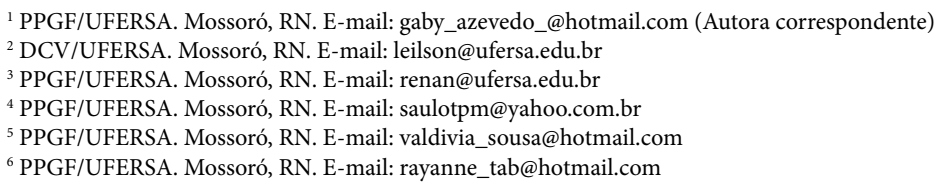

Palavras-chave:

Allium cepa L.

rendimento

cultivares

\begin{abstract}
R E S U M O
Propôs-se, neste trabalho, avaliar o desempenho agronômico da cebola em diferentes densidades de plantio, em Mossoró, RN. O delineamento experimental utilizado foi em blocos casualizados completos em esquema fatorial $2 \times 5$, com quatro repetições. Os tratamentos consistiram da combinação de duas cultivares de cebola (Vale Ouro IPA 11 e Bella Dura) e cinco densidades de plantio (80,120, 160, 200 e 240 plantas $\mathrm{m}^{-2}$ ). As características avaliadas foram: classificação dos bulbos em função do diâmetro transversal; produtividade total, comercial e não comercial; massa média dos bulbos; massa seca dos bulbos e relação do formato de bulbos. A cultivar mais produtiva foi a IPA 11, com produtividade total de $26,76 \mathrm{tha}^{-1}$. A densidade que proporcionou maior produtividade total $\left(30,48 \mathrm{t} \mathrm{ha}^{-1}\right)$ foi a de 204 plantas $\mathrm{m}^{-2}$ e comercial $\left(24,74 \mathrm{t} \mathrm{ha}^{-1}\right)$ foi a de 161 plantas $\mathrm{m}^{-2}$. O incremento da densidade reduziu a massa média e seca de bulbo, percentagem de bulbos das classes 2 e 3, mas aumentou a produtividade não comercial, percentagem de bulbos classe 1 (refugo) e relação de formato de bulbo. A cultivar Vale Ouro IPA 11 foi superior ao híbrido Bella Dura com relação à produtividade total de bulbos, massa média de bulbos comerciais e relação de formato, independentemente da densidade de plantio.
\end{abstract}

Key words: Allium cepa L. yield cultivars

\section{Production of onion grown under different planting densities}

\begin{abstract}
A B S T R A C T
The aim of this study was to evaluate the agronomic performance of onions in different planting densities in Mossoró, $\mathrm{RN}$. The experimental design used was a complete randomized blocks in factorial scheme $2 \times 5$, with four replications. The treatments consisted of the combination of two onion cultivars (Vale Ouro IPA 11 and Bella Dura) and five planting densities $\left(80,120,160,200\right.$ and 240 plants $\left.\mathrm{m}^{-2}\right)$. The evaluated characteristics were: classification of bulbs according to the transverse diameter; total, commercial and noncommercial productivity; mean mass of bulb, dry mass of bulb and relative format of bulbs. The most productive cultivar was IPA 11, with total productivity of 26.76 $\mathrm{t} \mathrm{ha}^{-1}$. The density that provided the greatest total productivity $\left(30.48 \mathrm{t} \mathrm{ha}^{-1}\right)$ was the 204 plants $\mathrm{m}^{-2}$ and commercial $\left(24.74 \mathrm{t} \mathrm{ha}^{-1}\right)$ was the 161 plants $\mathrm{m}^{-2}$. The increase in density reduced the average of medium and dry bulb mass, bulbs percentage of classes 2 and 3 as well as increased non-commercial yield, percentage of bulbs class 1 (waste) and relation of bulb shape. The cultivar Vale Ouro IPA 11 was superior to the hybrid Bella Dura regarding total bulb yield, average weight of commercial bulbs and format relations, regardless of plant density.
\end{abstract}

\section{INTRODUÇÃo}

A cebola (Allium cepa L.) é uma das hortaliças cultivadas mais importantes e utilizadas em todo o mundo. No Brasil, a cebola é considerada a terceira hortaliça mais influente, em termos de valor econômico, suplantada apenas pelo tomate e batata (Gonçalves et al., 2009). Em 2011 a produtividade média nacional foi de $23.996 \mathrm{~kg} \mathrm{ha}^{-1}$ (IBGE, 2011).

No Rio Grande do Norte a produção de cebola, de forma mais expressiva, é relativamente recente e se concentra nos municípios de Baraúna e Mossoró. A cebolicultura do estado difere daquela praticada nas demais regiões do Brasil, em que as altas produtividades são obtidas com populações superiores a 800.000 plantas por hectare chegando, em alguns casos, a ultrapassar 1 milhão de plantas (Rebouças et al., 2008) utilizando a semeadura direta e o sistema de irrigação por pivô central, sem a utilização de canteiros, os quais reduzem a área plantada; consequentemente, a população de plantas e a produtividade.

Os produtores potiguares cultivam cebola com a mesma tecnologia empregada no melão, ou seja, irrigação por gotejamento e aplicação de fertilizantes via água de irrigação. Além disso, a baixa densidade de plantio adotada pelos produtores de cebola do Rio Grande do Norte constitui-se como um dos principais fatores limitantes ao aumento da 
produtividade. Na maioria deles a população utilizada é em média 400.000 plantas por hectare, no sistema de transplantio de mudas em canteiros com a cultivar IPA 11; entretanto, embora a produtividade média do estado $\left(39,9 \mathrm{t} \mathrm{ha}^{-1}\right)$ seja superior à da região nordeste $\left(22,4 \mathrm{t} \mathrm{ha}^{-1}\right)$ e à brasileira $(23,9 \mathrm{t}$ $\mathrm{ha}^{-1}$ ) ela se mantém abaixo de outras regiões, como é o caso de Minas Gerais e Goiás, onde se chega a 57,6 e 70,8 t ha-1 (IBGE, 2011) respectivamente, fato que coloca os produtores locais em desvantagem, pois não conseguem competir com os produtores dessas regiões que, em razão da alta produtividade, reduz o preço da cebola.

O desempenho agronômico de uma espécie está relacionado tanto à sua adaptação local quanto às práticas de manejo fitotécnico (Menezes Júnior \& Vieira Neto, 2012). Dentre os fatores de manejo fitotécnico determinantes à produção comercial de bulbos o estabelecimento da população ideal de plantas por hectare se destaca para cada cultivar e sistema de cultivo (Baier et al., 2009).

Pesquisas realizadas nos últimos anos mostram diferentes resultados quanto ao aumento da densidade de plantio na produtividade da cebola dependendo da localidade, da cultivar utilizada e do manejo da cultura, entre outros fatores. Em trabalho realizado por Menezes Júnior \& Vieira Neto (2012) em Ituporanga (SC) utilizando a cultivar de cebola Empasc 355-Juporanga, esses autores verificaram que a produtividade total aumentou (de 33,58 para 41,92 $\mathrm{t} \mathrm{ha}^{-1}$ ) com o incremento da densidade de plantio (200 para $600 \mathrm{mil} \mathrm{plantas} \mathrm{ha}^{-1}$ ).

Da mesma forma, Baier et al. (2009) no Paraná, avaliando a cultivar Buccaneer em diferentes densidades de plantio (50, 75 e 100 plantas $\mathrm{m}^{-2}$ ) observaram que a maior produtividade comercial foi alcançada na maior densidade. Por outro lado, Rebouças et al. (2008) verificaram, em experimento realizado em Salinas (MG) utilizando o híbrido Mercedes e a cultivar Serrana em sistema de semeadura direta, que a produtividade comercial reduziu com o aumento da densidade de plantio (714.285 para 1.071.428 plantas ha-1).

Diante do exposto objetivou-se, neste trabalho, avaliar o desempenho agronômico de cebola em diferentes densidades de plantio em Mossoró, RN.

\section{Material e Métodos}

O experimento foi desenvolvido na área experimental do Departamento de Ciências Vegetais (DCV) da Universidade Federal Rural do Semiárido - UFERSA, Campus Mossoró, RN, localizado a $5^{\circ} 11^{\prime}$ de latitude sul, $37^{\circ} 20^{\prime}$ de longitude oeste de Greenwich e $18 \mathrm{~m}$ de altitude. O clima da região, segundo a classificação Köppen, é 'Bswh', isto é, seco e muito quente, com duas estações climáticas: uma seca, que em geral se estende de junho a janeiro e uma chuvosa, de fevereiro a maio (Carmo Filho et al., 1991).

O solo foi classificado como Argissolo Vermelho-Amarelo (EMBRAPA, 1999) textura franco arenosa, apresentando a seguinte composição química na camada de 0-0,20 m: $\mathrm{pH}\left(\mathrm{H}_{2} \mathrm{O}\right)$ $=7,44 ; \mathrm{MO}=5,73 \mathrm{~g} \mathrm{~kg}^{-1} ; \mathrm{P}=24,5 \mathrm{mg} \mathrm{dm}^{-3} ; \mathrm{K}^{+}=172,2 \mathrm{mg} \mathrm{dm}^{-3}$; $\mathrm{Na}^{+}=10,4 \mathrm{mg} \mathrm{dm}^{-3} ; \mathrm{Ca}^{2+}=2,37 \mathrm{cmol}_{\mathrm{c}} \mathrm{dm}^{-3} ; \mathrm{Mg}^{2+}=0,37 \mathrm{cmol}_{\mathrm{c}}$ $\mathrm{dm}^{-3} ; \mathrm{Al}^{3+}=0,00 \mathrm{cmol}_{\mathrm{c}} \mathrm{dm}^{-3} ; \mathrm{H}+\mathrm{Al}=0,00 \mathrm{cmol}_{\mathrm{c}} \mathrm{dm}^{-3} ; \mathrm{CTC}=$ $3,23 \mathrm{cmol}_{\mathrm{c}} \mathrm{dm}^{-3} ; \mathrm{V}=100 \%$.

O delineamento experimental utilizado foi em blocos casualizados (DBC) em esquema fatorial 2 x 5 com quatro repetições. Os tratamentos consistiram da combinação de duas cultivares de cebola (cultivar Vale Ouro IPA 11 e o Híbrido Bella Dura) com cinco densidades de plantio $(80,120,160$, 200 e 240 plantas $\mathrm{m}^{-2}$, que correspondem a 400.000, 600.000, $800.000,1.000 .000$ e 1.200 .000 plantas $\mathrm{ha}^{-1}$, respectivamente). O espaçamento utilizado entre fileiras foi de $0,10 \mathrm{~m}$ enquanto os espaçamentos entre plantas foram variáveis de acordo com as densidades.

Considerando como é realizado o plantio na região, ou seja, em um hectare se utilizam 25 canteiros com 200,0 m de comprimento e 1,0 $\mathrm{m}$ de largura, totalizando uma área efetivamente cultivada de $5.000 \mathrm{~m}^{2}$, a qual é utilizada para estimativa da produtividade para 1,0 ha desprezando-se os espaços entre os canteiros os quais não são plantados.

A unidade experimental foi constituída por um canteiro contendo oito fileiras de plantas com $3 \mathrm{~m}$ de comprimento, espaçadas $0,10 \mathrm{~m}$ perfazendo a área total de $3 \mathrm{~m}^{-2}$. As seis centrais foram consideradas área útil da parcelas excluindo-se uma planta de cada extremidade.

O preparo do solo constou de aração, gradagem e levantamento dos canteiros a $0,20 \mathrm{~m}$ de altura. A adubação de plantio constou da aplicação de fósforo na dose $70 \mathrm{~kg}$ ha $^{-1}$ de $\mathrm{P}_{2} \mathrm{O}_{5}$ na forma de superfosfato triplo de acordo com as recomendações baseadas na análise do solo e nas doses utilizadas pelos produtores de cebola da região.

As mudas foram produzidas em sementeira com dimensões de 0,80 m de largura e 0,20 de altura. Utilizaram-se $10 \mathrm{~g} \mathrm{~m}^{-2} \mathrm{de}$ semente para semeadura em sulcos paralelos ao comprimento do canteiro enquanto o transplantio foi realizado aos 40 dias após a semeadura (DAS) quando as mudas atingiram de 15 a $20 \mathrm{~cm}$ de altura.

O sistema de irrigação utilizado foi por gotejamento colocando-se uma mangueira na parte central do canteiro espaçada $0,3 \mathrm{~m}$ das outras, localizadas ao lado das fileiras bordaduras, com gotejadores do tipo autocompensante espaçados $0,20 \mathrm{~m}$, com vazão média de $1,5 \mathrm{~L} \mathrm{~h}^{-1}$. As irrigações foram realizadas diariamente e as lâminas foram determinadas com base na evapotranspiração da cultura (Allen et al., 1998).

A adubação de cobertura foi realizada diariamente via água de irrigação, utilizando-se tanque de derivação produzido com tubo de PVC conhecido na região como "pulmão". As fertirrigações foram iniciadas aos 10 dias após o transplantio (DAT), utilizando-se $90 \mathrm{~kg} \mathrm{ha}^{-1}$ de $\mathrm{N}, 125 \mathrm{~kg} \mathrm{ha}^{-1}$ de $\mathrm{K}_{2} \mathrm{O}$ e 70 $\mathrm{kg} \mathrm{ha}^{-1} \mathrm{de}_{2} \mathrm{O}_{5}$, nas formas de Uréia, Cloreto de Potássio, MAP, Nitrato de Cálcio, Nitrato de Potássio. Foi aplicado também 1 $\mathrm{kg} \mathrm{ha}^{-1}$ de Rexolin', como fonte de micronutrientes $(11,6 \%$ de $\mathrm{K}_{2} \mathrm{O}, 1,28 \%$ de $\mathrm{S}, 0,86 \%$ de $\mathrm{Mg}, 2,1 \%$ de $\mathrm{B}, 0,36 \%$ de $\mathrm{Cu}, 2,66 \%$ de $\mathrm{Fe}, 2,48 \%$ de $\mathrm{Mn}, 0,036 \%$ de $\mathrm{Mo}, 3,38 \%$ de $\mathrm{Zn}$ ), dividido em quatro aplicações quinzenais via fertirrigação.

O controle fitossanitário foi realizado com aplicação semanal, a partir dos 40 DAT. A colheita foi realizada aos 70 DAT quando $70 \%$ das plantas estavam tombadas. Após a colheita os 
bulbos permaneceram no campo durante três dias realizandose o processo de cura ao sol; em seguida foram levadas ao Laboratório de Recepção, do Departamento de Ciências Vegetais da UFERSA, onde permaneceram cinco dias para completar o processo de cura à sombra.

Decorrido o período de cura fez-se a toalete procedendo-se, a seguir, à avaliação das seguintes características de produção:

- Produtividade total dos bulbos $\left(\mathrm{t} \mathrm{ha}^{-1}\right)$ : obtida por meio da massa total dos bulbos colhidos na parcela;

- Produtividade dos bulbos comerciais $\left(\mathrm{t} \mathrm{ha}^{-1}\right)$ : obtida por meio da massa total dos bulbos de diâmetro maior que $35 \mathrm{~mm}$;

- Produtividade dos bulbos não comerciais $\left(\mathrm{t} \mathrm{ha}^{-1}\right)$ : obtida por meio da massa total dos bulbos de diâmetro menor que $35 \mathrm{~mm}$;

- Massa média dos bulbos comerciais (g): Produção comercial dividida pelo número dos bulbos comerciáveis colhidos na parcela;

- Relação de formato dos bulbos: Foram amostrados 10 bulbos e mensurados, por meio de um paquímetro digital, a altura e o diâmetro dos bulbos. Dividiu-se a altura pelo diâmetro para encontrar a relação de formato dos bulbos.

- Massa seca de bulbo: Foram amostrados 10 bulbos de cada parcela colocados em estufa com circulação de ar forçada a 65 ${ }^{\circ} \mathrm{C}$, até atingir massa constante;

A classificação dos bulbos foi realizada segundo as normas do Ministério da Agricultura Pecuária e Abastecimento (Brasil, 1995) baseada no diâmetro transversal, em:

- Classe 1 (bulbos com diâmetro maior que $35 \mathrm{~mm}$ )

- Classe 2 (bulbos com diâmetro entre 35 e $50 \mathrm{~mm}$ )

- Classe 3 (bulbos com diâmetro entre 50 e 75 mm)

- Classe 4 (bulbos com diâmetro entre 75 e $90 \mathrm{~mm}$ )

- Classe 5 (bulbos com diâmetro maior que 90 mm)

Os dados foram submetidos à análise de variância e quando ocorreu efeito significativo do fator qualitativo (cultivares) as médias foram comparadas pelo teste $\mathrm{F}$, e realizada a análise de regressão para o fator quantitativo (densidades) utilizando-se o programa Assistat versão 7.6 beta (Silva \& Azevedo, 2009).

\section{Resultados e Discussão}

A análise de variância revelou efeito significativo $(\mathrm{p}<0,01)$ dos fatores cultivar e densidade de plantio sobre a produtividade total (PT), massa média dos bulbos (MMB) e relação de formato (RF). Para as características produtividade comercial (PC), não comercial (PNC) o efeito foi significativo $(\mathrm{p}<0,01)$ da densidade e para massa seca dos bulbos (MSB) houve interação $(\mathrm{p}<0,05)$ entre os dois fatores. Verificou-se efeito significativo $(\mathrm{p}<0,01)$ das densidades sobre a porcentagem de bulbos nas diferentes classes (Tabela 1).

A produtividade não comercial (refugo) apresentou efeito linear crescente com o incremento da densidade aumentando de 1,18 para $11,71 \mathrm{t} \mathrm{ha}^{-1}$ (Figura 1A) ocorreu devida ao fato de que, à medida que se adensou, aumentou a produção de bulbos classe 1 (bulbos com diâmetro menor que $35 \mathrm{~mm}$ ), considerados não comerciais. Comportamento semelhante foi observado por Resende \& Costa (2005) os quais verificaram que o incremento da densidade, através da diminuição dos espaçamentos, aumentou a produtividade não comercial da cultivar Alfa Tropical e relataram que esses resultados mostram relação inversa entre o aumento ou redução da densidade de plantas na produtividade de bulbos de cebola. Em baixas populações se produz, geralmente, baixos rendimentos e alta porcentagem de bulbos médios e grandes. Porém em cultivos com densidades maiores que a ótima, apesar de maior produtividade tem-se bulbos pequenos e desuniformes de menor qualidade comercial (refugos), comparativamente ao cultivo em densidade adequada (Resende \& Costa, 2005).

A produtividade comercial apresentou efeito quadrático atingindo máximo estimado $\left(24,74 \mathrm{t} \mathrm{ha}^{-1}\right)$ na densidade de 161 plantas $\mathrm{m}^{-2}$ (Figura 1B). Lipinski et al. (2002) na Argentina, avaliaram quatro densidades de plantio $(30,40,50,60$ plantas $\mathrm{m}^{-2}$ ) e verificaram que a produtividade comercial aumentou até a densidade de 50 plantas $\mathrm{m}^{-2}$. No entanto, Baier et al. (2009) encontraram efeito linear crescente para produtividade comercial $\left(92,2 \mathrm{t} \mathrm{ha}^{-1}\right)$ com o incremento da densidade (50, 75 e 100 plantas $\mathrm{m}^{-2}$ ) enquanto Cecílio Filho et al. (2006) não constataram diferenças significativas para a produtividade comercial $\left(71,9\right.$ t ha $\left.^{-1}\right)$ em relação ao incremento das densidades de plantio $\left(60,76,92\right.$ e 108 plantas $\left.\mathrm{m}^{-2}\right)$.

A resposta da produtividade total ao aumento da densidade de plantio foi quadrática com maior produtividade estimada $30,48 \mathrm{t} \mathrm{ha}^{-1}$ obtida na densidade de 204 plantas $\mathrm{m}^{-2}$ (Figura 1C). Embora essa produtividade tenha sido superior à média nacional $\left(23,9 \mathrm{tha}^{-1}\right)$ e da região nordeste $\left(22,4 \mathrm{tha}^{-1}\right)$ ainda se

Tabela 1. Resumo da análise de variância para produtividade total (PT), produtividade comercial (PC), produtividade não comercial (PNC), massa média de bulbo (MMB), relação de formato do bulbo (RFB), massa seca de bulbo (MSB) e para porcentagem de bulbos nas diferentes classes ${ }^{\#}$ (Classe 1, Classe 2 e Classe 3) em função dos fatores cultivares e densidades de plantio

\begin{tabular}{|c|c|c|c|c|c|c|c|c|c|c|}
\hline \multirow{2}{*}{ F.V. } & \multirow{2}{*}{ G.L. } & \multicolumn{9}{|c|}{ Quadrado médio } \\
\hline & & PT & PC & PNC & MMB & RFB & MSB & Classe 1 & Classe 2 & Classe 3 \\
\hline Blocos & 3 & $2,50^{\mathrm{ns}}$ & $3,74^{\text {ns }}$ & $0,41^{\mathrm{ns}}$ & $1,13^{\text {ns }}$ & $0,003^{\mathrm{ns}}$ & $0,48 \mathrm{~ns}$ & $0,50^{\mathrm{ns}}$ & $1,09^{\mathrm{ns}}$ & $0,20^{\mathrm{ns}}$ \\
\hline Cult (C) & 1 & $48,27^{\star *}$ & $18,31^{\mathrm{ns}}$ & $7,12^{\mathrm{ns}}$ & 234,48 ** & $0,19 * *$ & 21,68 ** & $0,92^{\mathrm{ns}}$ & $4,06^{\mathrm{ns}}$ & $1,88^{\mathrm{ns}}$ \\
\hline Dens (D) & 4 & 184,48 ** & $117,45^{\star *}$ & $145,53^{* *}$ & 395,59 ** & $0,15^{\star \star}$ & $1,79 * *$ & $50,25^{\star \star}$ & $15,03^{* *}$ & 50,10 ** \\
\hline$C * D$ & 4 & $8,61^{\text {ns }}$ & $8,05^{\mathrm{ns}}$ & $5,38^{\mathrm{ns}}$ & $3,86^{\mathrm{ns}}$ & $0,01^{\text {ns }}$ & $1,19 *$ & $1,62^{\mathrm{ns}}$ & $0,83^{\mathrm{ns}}$ & $0,99^{\mathrm{ns}}$ \\
\hline Erro & 27 & & & & & & & & & \\
\hline CV (\%) & & 9,72 & 16,90 & 31,36 & 8,69 & 6,17 & 18,60 & 20,63 & 12,70 & 24,18 \\
\hline
\end{tabular}

ns não significativo; ** significativo a 0,01 de probabilidade; * significativo a 0,05 de probabilidade pelo Teste $\mathrm{F}$

\# Classe 1 - bulbos com diâmetro maior que 35 mm; Classe 2 - bulbos com diâmetro entre 35 e 50 mm; Classe 3 - bulbos com diâmetro entre 50 e 75 mm 
A.

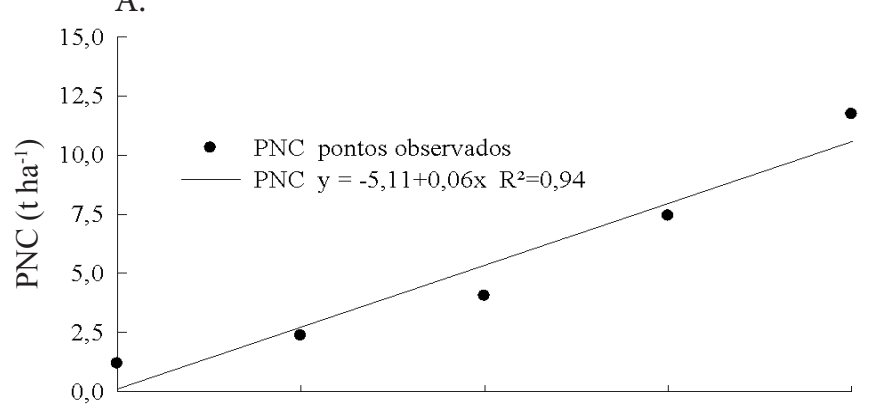

B.

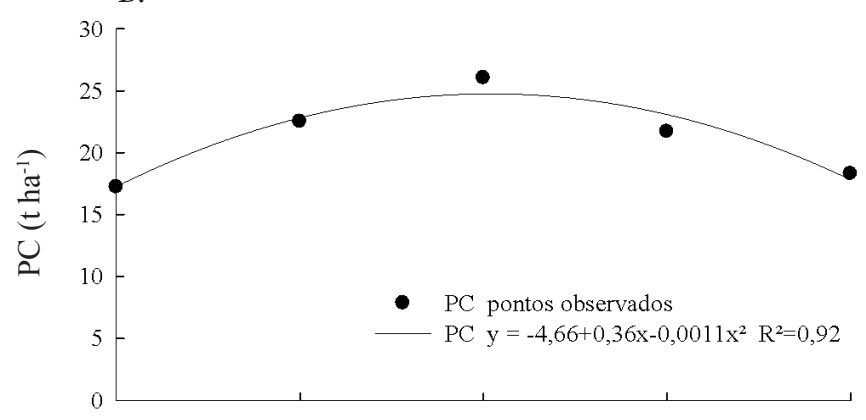

C.

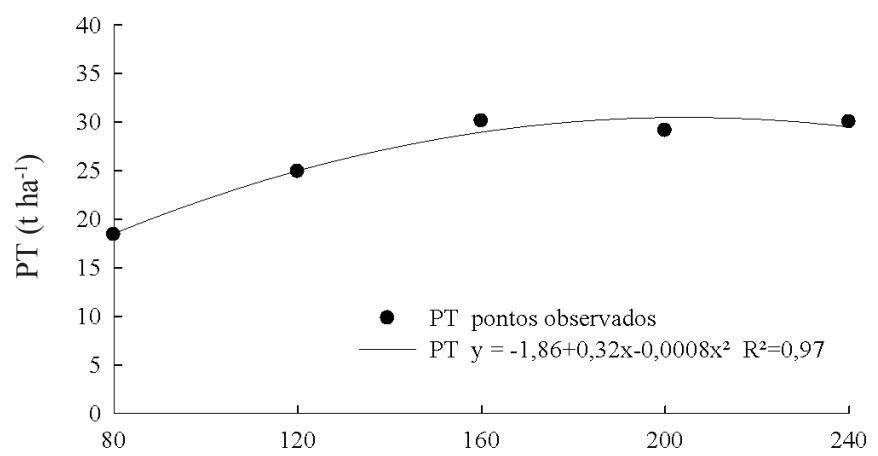

PNC - Produtividade não comercial; PC - Produtividade comercial; PT - Produtividade total

Densidade de plantio (plantas $\mathrm{m}^{-2}$ )

Figura 1. Produtividade não comercial - PNC (A), produtividade comercial - PC (B) e produtividade total - PT (C) de cebola em função das densidades de plantio

encontra inferior à média do estado do Rio Grande do Norte, que é de 39,9 tha ${ }^{-1}$ (IBGE, 2011). Dawar et al. (2007) verificaram, avaliando três cultivares de cebola (Swat-1, Terich-02, Gilassi local) em diferentes densidades de plantio no Paquistão, que o incremento da densidade proporcionou o aumento da produtividade total. Já Rebouças et al. (2008) observaram um decréscimo na produtividade total com o incremento da densidade $\left(714.285 ; 892.857 ; 1.071 .428\right.$ plantas ha $\left.^{-1}\right)$ com maior média de 40,21 $\mathrm{t} \mathrm{ha}^{-1}$ na menor densidade.

Entre as cultivares a IPA 11 apresentou maior produtividade total em relação ao híbrido Bela Dura (Tabela 2). Apesar do alto padrão genético normalmente apresentado pelos híbridos, a superioridade da IPA 11 pode estar relacionada ao fato da cultivar ser mais adaptada às condições de cultivo do semiárido nordestino mas este resultado foi diferente daqueles encontrados por Rebouças et al. (2008) e Vilas-Boas et al. (2011) que obtiveram maiores produtividades com os híbridos em relação às cultivares.
Tabela 2. Produtividade total (PT), massa média de bulbo (MMB) e relação de formato de bulbo (RFB) das cultivares IPA 11 e Bella Dura

\begin{tabular}{lccc}
\hline & $\begin{array}{c}\text { PT } \\
\mathbf{( t ~ h a}^{-1} \mathbf{)}\end{array}$ & $\begin{array}{c}\text { MMB } \\
\mathbf{( g )}\end{array}$ & RFB \\
IPA 11 & $26,76 \mathrm{a}$ & $45,89 \mathrm{a}$ & $1,38 \mathrm{a}$ \\
Bella Dura & $24,56 \mathrm{~b}$ & $41,05 \mathrm{~b}$ & $1,24 \mathrm{~b}$ \\
CV (\%) & 9,72 & 8,69 & 6,17 \\
\hline
\end{tabular}

As médias seguidas pela mesma letra na coluna não diferem estatisticamente entre si pelo Teste $\mathrm{F}$ de Snedecor ao nível de 0,01 de probabilidade

Verificou-se que o incremento da densidade de plantio aumentou o valor da relação de formato do bulbo, de 1,15 $\left(80\right.$ plantas $\left.\mathrm{m}^{-2}\right)$ para $1,46\left(240\right.$ plantas $\left.\mathrm{m}^{-2}\right)$ (Figura $2 \mathrm{~A}$ ), demonstrando que os bulbos ficaram mais alongados.

A relação de formato do bulbo é um caractere morfológico de grande importância visto que é um dos parâmetros utilizados para avaliar divergências genéticas entre as populações de cebola (Buzar et al., 2007). O híbrido Bella Dura apresentou relação de formato de bulbo significativamente menor que a cultivar IPA 11 (Tabela 2).

$\mathrm{O}$ aumento da densidade de plantio reduziu, de forma linear, a massa média dos bulbos (Figura 2B). Esta redução foi de $32,6 \%$ entre a menor ( 80 plantas $\mathrm{m}^{-2}$ ) e maior densidade (240 plantas $\mathrm{m}^{-2}$ ). A diminuição da massa média de bulbo com o incremento da densidade de plantio foi também observada por outros autores (Baier et al., 2009; Menezes Júnior \& Vieira

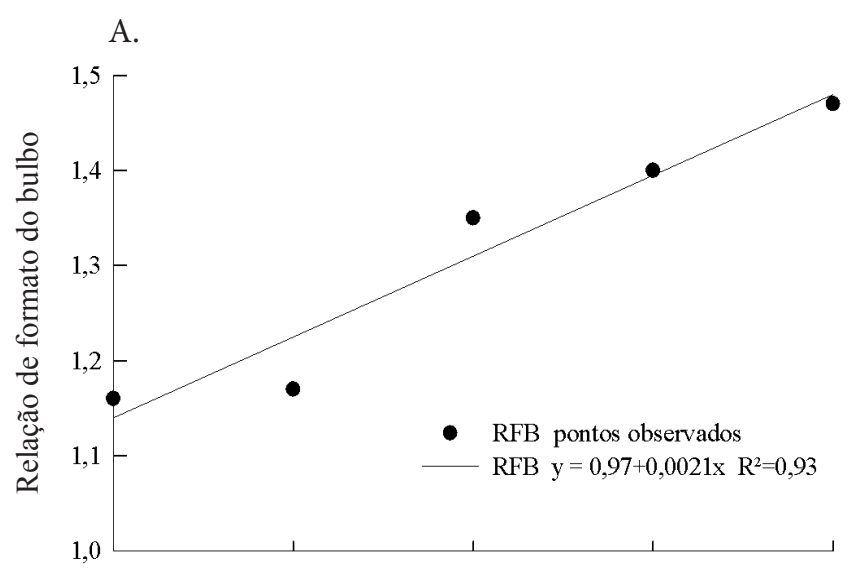

B.

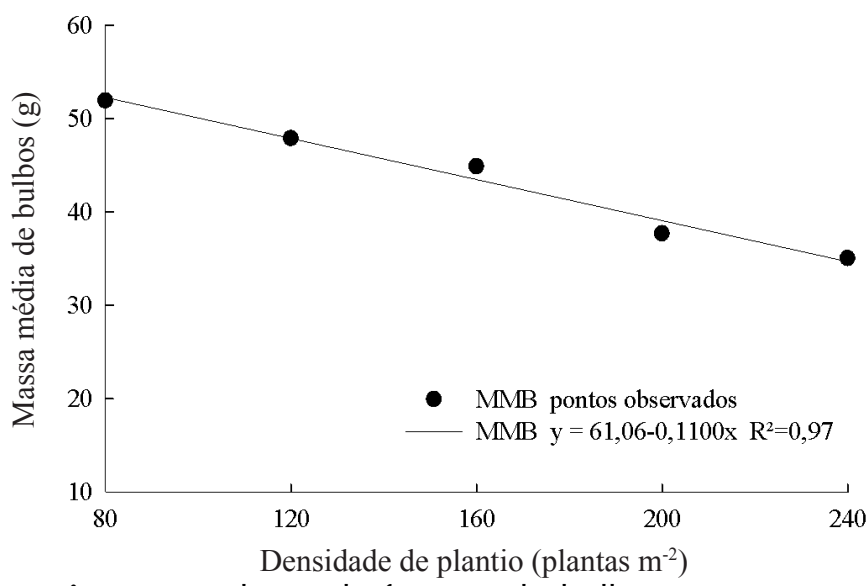

Figura 2. Relação de formato do bulbo - RFB (A) e massa média de bulbos de cebola - MMB (B) 
Neto, 2012) segundo os quais a maior massa fresca do bulbo obtida nas menores densidades está relacionada, provavelmente, à maior área de exploração das raízes e à menor competição pelos fatores de produção como água, luz e nutrientes. A cultivar IPA 11 apresentou massa média dos bulbos significativamente superior ao híbrido Bella Dura (Tabela 2).

Observou-se, no desdobramento da interação cultivar em cada densidade de plantio para a massa seca de bulbo, que com exceção da densidade de 200 plantas $\mathrm{m}^{-2}$ a cultivar IPA 11 foi superior ao híbrido Bella Dura (Tabela 3). A massa seca de bulbo da cultivar IPA 11 apresentou efeito linear decrescente com o aumento da densidade sofrendo uma redução de 5,15 para 3,27 g com o incremento da densidade de 80 para 240 plantas $\mathrm{m}^{-2}$. Para o híbrido Bella Dura ocorreu redução da massa seca de 3,13 g para 2,15 quando se aumentou a densidade de 120 plantas $\mathrm{m}^{-2}$ para 240 plantas $^{-2}$ (Figura 3 ).

De acordo com Rumpel \& Felczynski (2000) o uso de maiores densidades acelera a maturação de bulbos e, em contrapartida, há um crescimento menor da planta e menor acúmulo de massa seca por parte dos bulbos. O conteúdo de matéria seca é um importante fator de qualidade, sobremaneira para a indústria de processamento. Quanto maior o teor de matéria seca menor é a quantidade de energia exigida para o processo de desidratação (Soares et al., 2004). Diferente dos resultados obtidos neste trabalho, Cecílio Filho et al. (2009) observaram, avaliando duas cultivares e quatro populações de plantas, efeito significativo para massa seca de bulbo apenas para as cultivares com 14,77 g planta $^{-1}$ para a Optima, e 13,52 g planta $^{-1}$ para a Superex.

Em classificação dos bulbos de cebola observou-se, sempre que se aumentou a densidade de plantio, um incremento de forma linear na percentagem de bulbos classe 1, isto é, de bulbos considerados refugo reduzindo, assim, a produtividade comercial, o que não é interessante ao produtor considerando que os bulbos classe 1 têm baixo valor de mercado visto que são destinados à indústria enquanto na densidade de 80 plantas $\mathrm{m}^{-2}$ a produção foi de $17,2 \%$ de bulbos menores que $35 \mathrm{~mm}$ na densidade de plantio 240 plantas $\mathrm{m}^{-2}$ o percentual foi de $56,3 \%$ (Figura 4 ).

Diferente dos bulbos da classe 1 , o incremento da densidade de plantio reduziu a percentagem de bulbos das classes 2 e 3 . Para a classe 2 a redução foi de $58 \%$ para $42,7 \%$ e para a classe 3 houve um decréscimo de 29,6 para $5,4 \%$, respectivamente nas densidades de 80 e 240 plantas $\mathrm{m}^{-2}$ (Figura 4).

Cecílio Filho et al. (2006) observaram aumento dos bulbos classe 1 e redução dos bulbos classe 3 quando se aumentou a densidade de plantio de 60 para 108 plantas $\mathrm{m}^{-2}$. Concordando também com Rebouças et al. (2008) que verificaram que houve redução linear dos bulbos da classe 3 e incremento linear dos

Tabela 3. Médias da massa seca de bulbos (g) em função das cultivares nas densidades de plantio

\begin{tabular}{lccccc}
\hline \multirow{2}{*}{ Cultivares } & \multicolumn{5}{c}{ Densidades de plantio (plantas $\mathbf{~ m}^{-2}$ ) } \\
\cline { 2 - 6 } & $\mathbf{8 0}$ & $\mathbf{1 2 0}$ & $\mathbf{1 6 0}$ & $\mathbf{2 0 0}$ & $\mathbf{2 4 0}$ \\
IPA 11 & $5,15 \mathrm{a}$ & $4,37 \mathrm{a}$ & $3,99 \mathrm{a}$ & $3,32 \mathrm{a}$ & $3,27 \mathrm{a}$ \\
Bella Dura & $2,39 \mathrm{~b}$ & $3,13 \mathrm{~b}$ & $2,49 \mathrm{~b}$ & $2,57 \mathrm{a}$ & $2,15 \mathrm{~b}$ \\
\hline
\end{tabular}

As médias seguidas de mesma letra não diferem estatisticamente entre si pelo Teste de Snedecor ao nível de 0,01 de probabilidade

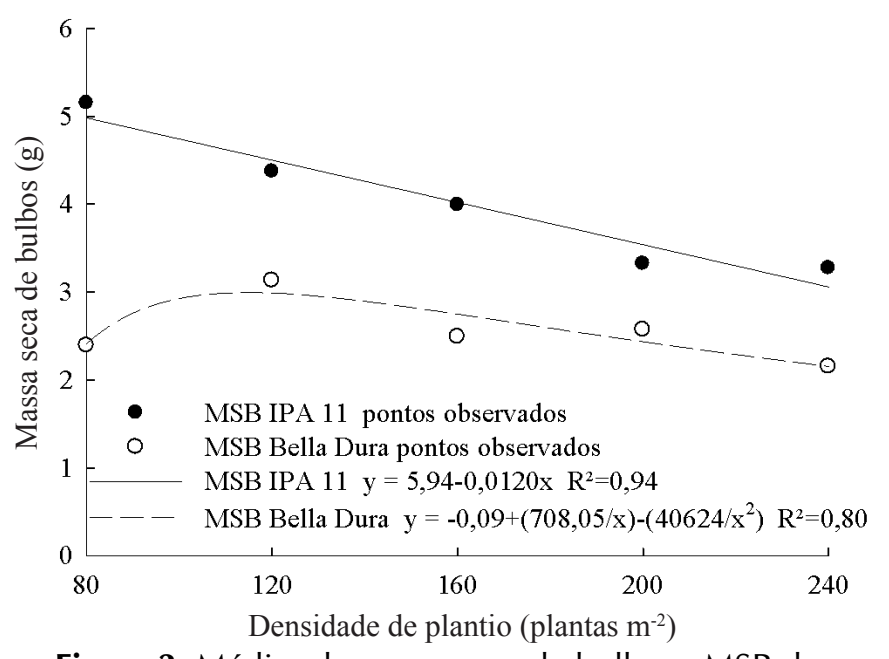

Figura 3. Médias da massa seca de bulbos - MSB das densidades de plantio em cada cultivar

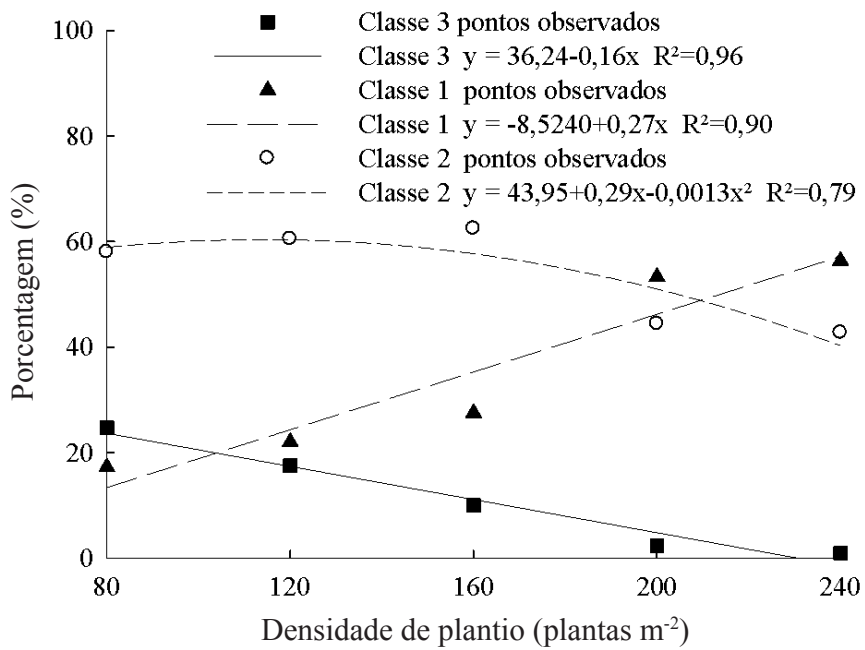

Figura 4. Porcentagem de bulbos nas diferentes classes $(1,2$ e 3$)$ em função da densidade de plantio

bulbos classe 1, quando se aumentou a densidade de 714.285 plantas ha ${ }^{-1}$ para 1.071.428 plantas ha-1. Segundo Baier et al. (2009), a classificação dos bulbos segundo o tamanho é um indicador da qualidade da produtividade alcançada.

\section{Conclusões}

1. A cultivar Vale Ouro IPA 11 foi superior ao híbrido Bella Dura com relação à produtividade total de bulbos, massa média de bulbos comerciais e relação de formato, independentemente da densidade de plantio.

2. O incremento da densidade reduziu a massa média e seca de bulbo, percentagem de bulbos das classes 2 e 3, bem como aumentou a produtividade não comercial, percentagem de bulbos classe 1 (refugo) e relação de formato de bulbo.

\section{Agradecimentos}

Ao CNPq - Conselho Nacional de Desenvolvimento Científico e Tecnológico, pela concessão da bolsa. 


\section{Literatura Citada}

Allen, R. G.; Pereira, L. S.; Raes, D.; Smith, M. Crop evapotranspiration: guidelines for computing crop water requirements. Rome: FAO 1998. 300p. Irrigation and Drainage Paper, 56

Baier, J. E.; Resende, J. T. V.; Galvão, A. G.; Battistelli, G. M.; Machado, M. M.; Faria, M. V. Produtividade e rendimento comercial de bulbos de cebola em função da densidade de cultivo. Ciência e Agrotecnologia, v.33, p.496-501, 2009.

Brasil. Ministério da Agricultura, Abastecimento e Reforma Agrária, Portaria n. 529 de 18 ago. 1995. Diário Oficial da República Federativa do Brasil, Brasília, 1 set. 1995. Seção 1, p.13513.

Buzar, A. G. R.; Oliveira, V. R.; Boiteux, L. S. Estimativa da diversidade genética de germoplasma de cebola via descritores morfológicos, agronômicos e bioquímicos. Horticultura Brasileira, v.25, p.527-532, 2007.

Carmo Filho, F.; Espínola Sobrinho, J.; Maia Neto, J. M. Dados climatológicos de Mossoró: um município semi-árido nordestino. Mossoró: ESAM, 1991. 121p.

Cecílio Filho, A. B.; May, A.; Pôrto, D. R. Q.; Barbosa, J. C. Crescimento da cebola em função de doses de nitrogênio, potássio e da população de plantas em semeadura direta. Horticultura Brasileira, v.27, p.49-54, 2009.

Cecílio Filho, A. B.; May, A.; Pôrto, D. R. Q.; Stein, R. C.; Vargas, P. F. Produtividade e qualidade de bulbos de duas cultivares de cebola em função da população de plantas, em semeadura direta. Caatinga, v.19, p.146-152, 2006.

Dawar, Effect of planting density on growth and yield of onion varieties under climatic conditions of Peshawar. Sarhad Journal of Agriculture, v.23, p.911-918, 2007.

EMBRAPA - Empresa Brasileira de Pesquisa Agropecuária Sistema brasileiro de classificação de solos. Brasília: Embrapa Produção de Informações (SPI), 1999. 412p.
Gonçalves, P. A. S.; Wordell Filho, J. A.; Kurtz, C. Efeitos da adubação sobre a incidência de tripes e míldio e na produtividade da cultura da cebola. Revista Agropecuária Catarinense, v.22, p.57-60, 2009.

IBGE - Instituto Brasileiro de Geografia e Estatística. Produção agrícola municipal. Culturas temporárias e permanentes. Rio de Janeiro: IBGE, 2011.97p.

Lipinski, V. M.; Gaviola, S.; Gaviola, J. C. Efecto de la densidad de plantación sobre el rendimiento de cebolla cv. Cobriza Inta con riego por goteo. Agricultura Técnica, v.62, p.574$582,2002$.

Menezes Júnior, F. O. G.; Vieira Neto, J. Produção da cebola em função da densidade de plantas. Horticultura Brasileira, v.30, p.733-739, 2012.

Rebouças, T. N. H.; Siqueira, L. G.; Lemos, O. L.; Grisi, F. A. Densidade de plantio em cebola no sistema de semeadura no norte de Minas Gerais. Magistra, v.20, p.78-86, 2008.

Resende, G. M.; Costa, N. D. Produtividade e armazenamento de cebola, cv. Alfa Tropical, cultivada em diferentes espaçamentos. Horticultura Brasileira, v.23, p.1010-1014, 2005.

Rumpel, J.; Felczynski, K. Effect of plant density on yield and bulb size of direct sown onions. Acta Horticulturae, v.1, p.179-186, 2000.

Silva, F. de A. S. e; Azevedo, C. A. V. de. Versão do programa computacional Assistat para o sistema operacional Windows. Revista Brasileira de Produtos Agroindustriais, v.4, p.71-78, 2009.

Soares, V. L. F.; Finger, F. L.; Mosquim, P. R. Influência do genótipo e do estádio de maturação na colheita sobre a matéria fresca, qualidade e cura dos bulbos de cebola. Horticultura Brasileira, v.22, p.18-22, 2004.

Vilas-Boas, R. C.; Pereira, G. M.; Souza, R. J.; Consoni, R. Desempenho de cultivares de cebola em função do manejo da irrigação por gotejamento. Revista Brasileira de Engenharia Agrícola Ambiental, v.15, p.117-124, 2011. 